\title{
Corrida de bolinhas: reflexão sobre o uso do conceito de movimento e de conservação de energia mecânica ${ }^{+*}$
}

Silmar Antonio Travain ${ }^{1}$

Alice Assis ${ }^{1}$

José Lourenço Cindra ${ }^{1}$

Faculdade de Engenharia de Guaratinguetá

UNESP - Universidade Estadual Paulista

Guaratinguetá - SP

\section{Resumo}

Neste trabalho, propõe-se o uso de uma atividade experimental de demonstração, intitulada "corrida de bolinhas", para que seja usada com o objetivo de discutir conceitos de movimento e de conservação de energia mecânica, a partir de uma situação problema envolvendo esses conceitos. $O$ uso dessa atividade de forma aberta pode propiciar o interesse do aluno em aprender e, com isso, viabilizar seu envolvimento cognitivo com os conceitos trabalhados. Isso também pode facilitar o desenvolvimento de habilidades que permitam aos alunos a elaboração de explicações coerentes, para o fenômeno observado, fundamentadas nos conceitos envolvidos.

Palavras-chave: Ensino de Física; Atividade de Demonstração Aberta; Conceitos de Movimento e Conservação de Energia Mecânica.

\begin{abstract}
In this paper, it is proposed the use of an experimental activity entitled ball race with the purpose of discussing the concepts of motion and the conservation of mechanical energy, from a problem situation involving
\end{abstract}

\footnotetext{
${ }^{+}$Ball race: reflection on the use of the concept of motion and the conservation of mechanical energy

* Recebido: novembro de 2017.

Aceito: maio de 2018.

${ }^{1}$ E-mails: satravain@feg.unesp.br; aliassis@gmail.com; jlcindra@uol.com.br
} 
these concepts. The use of this activity in an open way can foster the students' interest in learning and, with this, enable their cognitive involvement with the worked concepts. It's supposed that this activity may facilitate the development of skills by the students, allowing them to elaborate coherent explanations for the phenomena observed, based on the underlying concepts.

Keywords: Physics teaching; Open Demonstration Activity; Concepts of Motion and Conservation of Mechanical Energy.

\section{Introdução e fundamentação teórica}

Muitas pesquisas, na área de Ensino de Ciências, destacam a importância do uso de estratégias "que incentivem os estudantes a se envolverem em exercícios de construção, avaliação e revisão de modelos explicativos e que os estimulem a pensar qualitativamente com tais modelos" (BORGES, 2006, p. 136). Nessa perspectiva, é primordial que o aluno seja levado a refletir mediante situações distintas, a fim de que possa formular hipóteses e discutir a validade de suas explicações no contexto de sala de aula.

Segundo Oliveira (2010, p. 144),

O raciocínio lógico para interligar as informações teóricas e os fenômenos observados experimentalmente, a capacidade de elaborar explicações coerentes para os dados obtidos à luz do conhecimento científico são habilidades que raramente são desenvolvidas nos alunos em estratégias de ensino tradicionais, nas quais cabe ao professor organizar e apresentar todas as informações sobre os fatos e conceitos em questão.

Para que os alunos desenvolvam essas habilidades, é fundamental que o professor assuma uma postura que os levem a fazer escolhas e tomar decisões, de forma a tornarem-se "intelectualmente ativos", o que pode ser viabilizado por meio de atividades experimentais investigativas (BIASOTO; CARVALHO, 2007).

No entanto, é importante destacar que o simples fato de os alunos manipularem os equipamentos no decorrer das atividades não implica "que eles estejam participando ativamente do processo de aprendizagem, pelo contrário, continuam como sujeitos passivos", como apontam Daher e Machado (2017, p. 2).

Segundo Azevedo (2004), para que a atividade seja investigativa,

a ação do aluno não deve se limitar apenas ao trabalho de manipulação ou observação, ela deve também conter características de um trabalho científico: o aluno deve refletir, discutir, explicar relatar, o que dará ao seu trabalho as características de uma investigação científica (AZEVEDO, 2004, p. 21). 
Para Zômpero e Laburú (2011), tais atividades devem contribuir para que os alunos desenvolvam habilidades cognitivas, elaborem hipóteses, anotem e analisem dados e desenvolvam a capacidade argumentativa.

Wartha e Lemos (2016) ressaltam que trabalhar com os alunos sob a ótica da abordagem investigativa implica em

mobilizar o estudante a aprender ciências, não da maneira como os cientistas fazem em seus laboratórios, mas sim, apropriando-se de práticas dos cientistas como por exemplo, a curiosidade, a dúvida, a argumentação, a explicação, o compartilhamento das ideias e a própria reformulação das ideias (p. 7).

Para tanto, se faz necessário instigá-los para que questionem, elaborem e exponham os seus modelos explicativos, de forma intelectualmente ativa (WARTHA; LEMOS, 2016).

Nessa perspectiva, o ensino de ciências por investigação privilegia "a participação do aluno como ser pensante e ativo no processo de construção do conhecimento, tendo o professor como mediador do processo" (BAYERL, 2014, p. 40). Segundo Força, Laburú e Silva (2011), essas atividades devem propiciar a interação em sala de aula, de forma a valorizar tal participação dos alunos, expondo suas ideias, colocando suas hipóteses e discutindo os resultados.

Nesse sentido, no presente artigo, sugerimos que seja usada, em aulas de física, uma atividade experimental de demonstração que seja desenvolvida de modo distinto do habitual, ou seja, que não seja aplicada "nos moldes da experiência de cátedra em que professor manipula o equipamento, demonstra a experiência, buscando induzir determinadas conclusões" (FORÇA; LABURÚ; SILVA, 2011).

Kasseboehmer (2015, apud MONTEIRO; RODRIGUES; SANTIN, 2017) aponta que uma das formas de se dar a investigação pode ser por meio da problematização de uma situação que leve os alunos a formularem explicações acerca do fenômeno em questão usando conceitos científicos. Nesse contexto, Araújo e Abib (2003) destacam que a atividade de demonstração pode ser utilizada de forma aberta, explorando ao máximo suas potencialidades, de forma a superar a mera exposição de um fenômeno, o que propicia

uma maior abertura e flexibilidade para discussões que podem permitir um aprofundamento nos aspectos conceituais e práticos relacionados com os equipamentos, a possibilidade de se levantar hipóteses e o incentivo à reflexão crítica, de modo que a demonstração consistiria em um ponto de partida para a discussão sobre os fenômenos abordados, com possibilidade de exploração mais profunda do tema estudado (ARAÚJO; ABIB, 2003, p. 181).

Por apresentar várias características próprias das atividades investigativas, os autores classificam a atividade de demonstração aberta como de caráter investigativo. A condução de tal atividade por meio da problematização permite que os alunos exerçam a capacidade de reflexão, desenvolvam a criatividade e avaliem as suas hipóteses. 
Levar os alunos à reflexão acerca do fenômeno observado, permitindo que eles coloquem e discutam as suas concepções, pode estimular o interesse pelos conhecimentos abordados. Isso pode contribuir para o desenvolvimento de "habilidades, atitudes e competências relacionadas ao fazer e entender a Ciência" (ARAÚJO; ABIB, 2003, p. 191), favorecendo assim uma aprendizagem profícua dos conhecimentos abordados.

Neste trabalho, propomos o uso da atividade de demonstração, intitulada "corrida de bolinhas", com o objetivo de desenvolver, em sala de aula, os conceitos de movimento e de conservação de energia mecânica, por meio de uma abordagem aberta a partir de uma situação problema que permita aos alunos formularem explicações envolvendo esses conceitos.

\section{O experimento}

O presente trabalho tem como objetivo apresentar uma proposta de uma atividade experimental de demonstração, para ser aplicada de forma investigativa, em aulas de física do Ensino Médio. Para tanto, deve ser abordada de forma aberta, de modo a permitir que os alunos participem ativamente colocando e discutindo as suas hipóteses, sendo incentivados a refletirem criticamente acerca do fenômeno observado.

O experimento "corrida de bolinhas" (Fig. 1) é constituído por dois trilhos, sendo o primeiro horizontal de comprimento L por onde rola uma pequena esfera, sem deslizar. Seja $\mathrm{V}_{0}$ a velocidade da esfera no ponto inicial $\left(\mathrm{A}_{1}\right)$ do percurso e $E=\frac{m V_{0}^{2}}{2}$ a sua energia mecânica total. Já que, em princípio, essa velocidade é constante, o corpo percorre a distância L em um intervalo de tempo $t_{0}=\frac{L}{V_{0}}$.

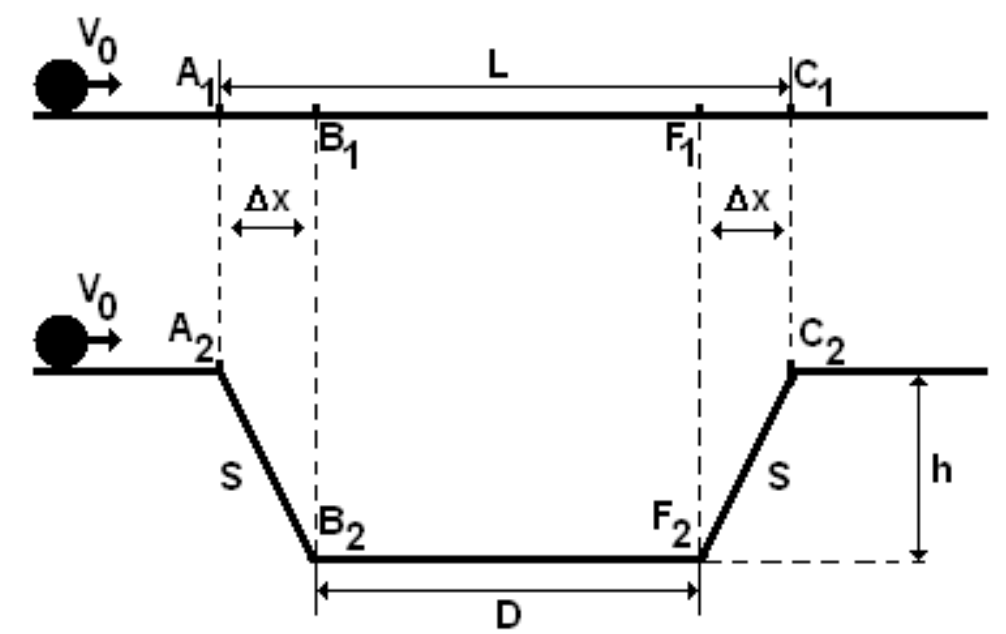

Fig. 1 - Esquema para a montagem experimental.

O segundo trilho tem início no mesmo nível do primeiro trilho. Porém, em seguida, possui um declive de profundidade h, seguido de um trecho horizontal de comprimento D e, finalmente, um aclive de altura h, de modo que volta ao mesmo nível horizontal inicial. Uma 
esfera semelhante à utilizada no primeiro trilho (mesmo raio e mesma massa) tem, no ponto $\mathrm{A}_{2}$ (equivalente à posição $\mathrm{A}_{1}$ ), a mesma velocidade $\mathrm{V}_{0}$ que a esfera do primeiro trilho no ponto $\mathrm{A}_{1}$. Ela rola sem deslizar ao longo do declive, continua a rolar sem deslizamento ao longo do trecho $\mathrm{D}$, subindo o aclive e voltando ao mesmo nível do primeiro trilho, a partir do ponto $\mathrm{C}_{2}$.

A abordagem deste experimento pode ser iniciada a partir da colocação do seguinte problema: qual das duas esferas deve chegar primeiro nos pontos finais $\left(\mathrm{C}_{1}\right.$ e $\left.\mathrm{C}_{2}\right)$ ?

Considerando que, usualmente, o conteúdo abordado anteriormente à aplicação dessa atividade corresponde à conservação da energia mecânica, é provável que os alunos respondam a esse problema fundamentados nessa conservação, colocando como hipótese que as duas esferas devem chegar aos referidos pontos simultaneamente. Essa hipótese pode ser decorrente do fato de os dois trilhos possuírem a mesma altura inicial (pontos $\mathrm{A}_{1}$ e $\mathrm{A}_{2}$ ) e final (pontos $\mathrm{C}_{1}$ e $\mathrm{C}_{2}$ ).

Ponderamos que os alunos usariam a referida hipótese para responder ao problema colocado, porque, ao apresentarmos esse experimento durante uma feira de exposição aberta à comunidade, realizada no Departamento de Física de uma universidade, consultamos verbalmente vários estudantes do curso de física, bem como professores de física (teórica e experimental) e observamos que $90 \%$ deles consideraram que as duas esferas deveriam chegar ao ponto final ao mesmo tempo e $10 \%$ acreditavam que a esfera que percorria o primeiro trilho (menor percurso) chegaria antes, conforme apresentado na Tabela 1. No entanto, mediante a realização do experimento, essas hipóteses foram refutadas, pois a esfera que percorre o segundo trilho atinge o ponto $C_{2}$ antes que a primeira esfera atinja o ponto $C_{1}$. É importante ressaltar que esses dados foram obtidos informalmente, uma vez que não foi feita uma investigação sistemática.

Tabela 1 - Opinião dos participantes (professores e alunos de Física) em consulta informal sobre o movimento das esferas no experimento das bolinhas.

\begin{tabular}{|c|c|c|c|}
\hline & $\begin{array}{l}\text { Número de Partici- } \\
\text { pantes }\end{array}$ & $\begin{array}{l}\text { Esferas chegam ao } \\
\text { mesmo tempo }\end{array}$ & $\begin{array}{l}\text { Esfera do primeiro } \\
\text { trilho é mais rápida }\end{array}$ \\
\hline $\begin{array}{l}\text { Professores Física } \\
\text { Teórica }\end{array}$ & 8 & 8 & 0 \\
\hline $\begin{array}{l}\text { Professores Física } \\
\text { Experimental }\end{array}$ & 3 & 3 & 0 \\
\hline $\begin{array}{l}\text { Alunos Graduação em } \\
\text { Física }\end{array}$ & 43 & 38 & 5 \\
\hline $\begin{array}{l}\text { Alunos Pós- } \\
\text { Graduação em Física }\end{array}$ & 12 & 10 & 2 \\
\hline \multirow[t]{2}{*}{ Total participantes } & 66 & 59 & 7 \\
\hline & $100 \%$ & $89,4 \%$ & $10,6 \%$ \\
\hline
\end{tabular}


Considerando esses resultados, desenvolvemos a presente proposta para que seja aplicada em sala de aula visando propiciar discussões a respeito do problema em questão e acreditamos que as respostas dos alunos devem ser condizentes com aquelas apresentadas na Tabela 1. Como o experimento evidencia uma situação que se contrapõe a essas respostas, é imprescindível que o professor dê abertura para que os alunos exerçam a reflexão, coloquem e discutam novas hipóteses a fim de viabilizar um aprofundamento conceitual. É importante ressaltar que o papel do professor enquanto mediador do processo de construção de conhecimento por parte dos alunos é fundamental.

Nessa perspectiva, o professor pode mediar a discussão no sentido de dirigir o raciocínio lógico dos alunos, para que eles possam fazer a articulação entre o referido resultado e os vários conceitos envolvidos na situação do experimento. Embora o princípio da conservação da energia mecânica, em geral, facilite a resolução de problemas de dinâmica, na presente situação, também é necessária a utilização de conceitos de cinemática. O referido princípio explica o fato de as duas esferas atingirem os pontos finais $\left(\mathrm{C}_{1}\right.$ e $\left.\mathrm{C}_{2}\right)$ com a mesma velocidade, porém, neste caso em particular, ter a mesma velocidade nesses pontos não implica que os trajetos são percorridos no mesmo intervalo de tempo.

Considerando que, no trilho 2, a partir do ponto $\mathrm{A}_{2}$ há um declive no trajeto, a esfera, durante esse declive, tem a sua velocidade aumentada, chegando no ponto $\mathrm{B}_{2}$ com uma velocidade $\mathrm{V}>\mathrm{V}_{0}$, enquanto a esfera no trilho 1 mantém constante a velocidade $\mathrm{V}_{0}$. Com isso, a esfera do trilho 2 desloca-se no trecho D com uma velocidade constante maior que a da outra esfera. Mesmo quando ela atinge o aclive e retorna à altura inicial, essa esfera já se encontra adiantada em relação à primeira. Com isso, ainda que as duas esferas atinjam os pontos finais $\left(\mathrm{C}_{1}\right.$ e $\left.\mathrm{C}_{2}\right)$ com a mesma velocidade, o tempo de percurso da segunda esfera é menor que o tempo de percurso da primeira.

Assim, para responder ao problema inicialmente colocado, é necessário recorrer aos conceitos de cinemática para determinar o tempo de percurso das esferas nos trilhos. A seguir, demonstramos esse resultado.

\section{II.1 Demonstração}

Para o corpo que percorre o trilho 1 , horizontal, temos

$$
t=\frac{L}{V_{0}}=\frac{(D+2 \Delta x)}{V_{0}}=\frac{D}{V_{0}}+\frac{2 \Delta x}{V_{0}}
$$

No tocante ao corpo que se move ao longo do trilho 2, no ponto $\mathrm{A}_{2}$ imediatamente antes do declive, a velocidade é $\mathrm{V}_{0}$, mas, na base desse declive a velocidade deve ser maior e correspondendo a:

$$
V=\sqrt{V_{0}^{2}+2 g h}
$$


Vamos representar por $\mathrm{S}$ os comprimentos dos trechos em declive e aclive: $S=V_{m} \Delta t=\frac{1}{2}\left(V_{0}+V\right) \Delta t_{A D}$. Portanto, isolando o $\Delta \mathrm{t}_{A D}$ (tempo necessário para percorrer o aclive ou o declive), obtemos: $\Delta t_{A D}=\frac{2 S}{\left(V_{0}+V\right)}$. Como temos duas inclinações (um aclive e um declive), o tempo total dessas duas inclinações será $2 \Delta \mathrm{t}_{A D}$. Assim, considerando os dois trechos inclinados, obtemos $\Delta t=\frac{4 S}{\left(V_{0}+V\right)}$. Nesse mesmo trilho 2, o outro trecho horizontal de comprimento D é percorrido no tempo $\mathrm{t}_{1}$, com uma velocidade constante $\mathrm{V}$ :

$$
t_{1}=\frac{D}{V}
$$

Com isso, o tempo total transcorrido durante todo o movimento da esfera ao longo do trilho 2 será:

$$
t_{2}=t_{1}+\Delta t
$$

Visando relacionar as velocidades $\mathrm{V}_{0}$ (trilho 1) e V (trilho 2) no percurso horizontal $\mathrm{D}$, representamos por $\mathrm{t}_{0} \mathrm{o}$ intervalo de tempo para que a esfera no trilho 1 percorra a distância $\mathrm{D}$, com velocidade $\mathrm{V}_{0}$.

$$
t_{0}=\frac{D}{V_{0}}
$$

Portanto, igualando as distâncias D nas equações 3 e 5 , obtemos $V t_{1}=V_{0} t_{0}$, relacionando $\frac{t_{0}}{t_{1}}$

$$
\frac{t_{0}}{t_{1}}=\frac{V}{V_{0}}=\frac{\sqrt{V_{0}^{2}+2 g h}}{V_{0}}>1
$$

Consequentemente, a esfera que percorre o caminho que apresenta declive e aclive percorre seu comprimento horizontal em um intervalo de tempo menor, se comparado com o mesmo percurso (distância D) percorrido pela outra esfera no trilho correspondente. No trilho somente horizontal (trilho 1), a esfera se movimenta sempre com a mesma velocidade $\mathrm{V}_{0}$.

Entretanto, ainda não comparamos o intervalo de tempo gasto para percorrer o trecho $2 \Delta x=A_{1} B_{1}+F_{1} C_{1}$ no trilho 1 , com o intervalo de tempo gasto para percorrer a distância $2 S=A_{2} B_{2}+F_{2} C_{2}$ em declive e aclive no trilho 2. Seja $\Delta t_{0}=\frac{2 \Delta x}{V_{0}}$ e $\Delta t=\frac{2 S}{V_{m}}$. Como já vimos, a velocidade média nos trechos inclinados é $V_{m}=\frac{1}{2}\left(V_{0}+V\right)$. Logo, temos:

$$
\frac{\Delta t_{0}}{\Delta t}=\left(1+\frac{V}{V_{0}}\right) \frac{\Delta x}{2 S}
$$


Apesar da expressão entre parênteses $\left(1+\frac{V}{V_{0}}\right)$ ser maior que dois, o fator $\frac{\Delta x}{2 S}$ é menor que um, podendo até ser muito pequeno, se a descida e a subida (referente á inclinação $S$ ) forem muito íngremes. Portanto, não podemos concluir que $\frac{\Delta t_{0}}{\Delta t}>1$. Pode-se observar que o tempo total gasto pela esfera que segue o percurso horizontal L é $t=t_{0}+\Delta t_{0}$, enquanto a segunda esfera gasta o intervalo de tempo $t_{2}=t_{1}+\Delta t$ para percorrer todo o percurso. Já vimos que a relação $\frac{t_{0}}{t_{1}}>1$, mas não sabemos se $\frac{\Delta t_{0}}{\Delta t}$ é maior ou menor que 1. Entretanto, levando em conta que $\mathrm{S}<<\mathrm{D}$, os intervalos de tempo $\Delta \mathrm{t}_{0}$ e $\Delta \mathrm{t}$ são ambos muito pequenos, se comparados $t_{0}$ e $t_{1}$, respectivamente. Assim, podemos concluir que a diferença $\left(\Delta t_{0}-\Delta t\right)$, ainda que tenha um valor negativo, não é capaz de alterar a condição: $\left(t-t_{2}\right)>0$.

Portanto, podemos concluir que a esfera que percorre, no trilho 2, o caminho $\mathrm{A}_{2} \mathrm{C}_{2}$, constituído de um trecho em declive e comprimento $\mathrm{S}$, seguido de um percurso horizontal de comprimento D e terminando com um trecho em aclive, de comprimento $\mathrm{S}$, percorre todo o caminho em um tempo $t_{2}=t_{1}+\Delta t$ (equação 4), menor que o tempo $\mathrm{t}$ (equação 1 ) gasto para a esfera percorrer a distância horizontal $\mathrm{L}$, no trilho 1 , compreendida entre os pontos $\mathrm{A}_{1}$ e $\mathrm{C}_{1}$.

\section{Observações que julgamos necessárias}

A velocidade $V=\sqrt{V_{0}^{2}+2 g h}$ foi obtida ao tratar o movimento da esfera de raio $\mathrm{r}$ que rola sem deslizar, como se fosse o movimento de um bloco que desliza sem atrito. Entretanto, se levarmos em consideração que, em se tratando de uma esfera que rola sem deslizar, além da energia cinética do movimento de translação do centro de massa, há também a energia cinética associada ao movimento de rotação.

No ponto em que começa o trecho de altura h e comprimento $S$, em declive, a energia total é $E=\frac{m V_{0}^{2}}{2}+\frac{I_{C} \omega_{0}^{2}}{2}=\frac{m V_{0}^{2}}{2}+\frac{m V_{0}^{2}}{5}=\frac{7 m V_{0}^{2}}{10}$ e no ponto em que começa o trecho horizontal D, temos $E=\frac{7 m V^{2}}{10}-m g h, \operatorname{logo}$ :

$$
V=\sqrt{V_{0}^{2}+\frac{10}{7} g h}
$$

Portanto, o valor da velocidade $\mathrm{V}$, na expressão (8), deve ser menor que o valor indicado na expressão (2), mas isso não altera as conclusões sobre a desigualdade dos tempos, estimada, de acordo com as considerações (5) e (6) e nem as considerações feitas na expressão (7).

\section{II.2 A construção do experimento}

Para a construção do experimento são necessários os seguintes materiais: 
2 (duas) bases de madeira $(12 \times 5 \times 8) \mathrm{cm}$

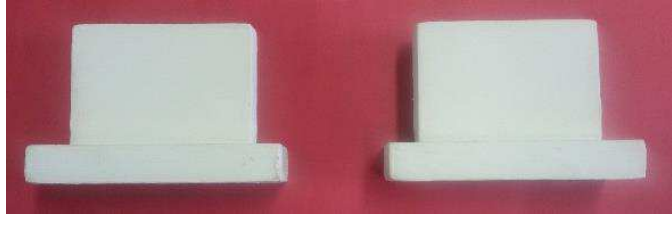

Fig. 2a-Vista lateral base de madeira.

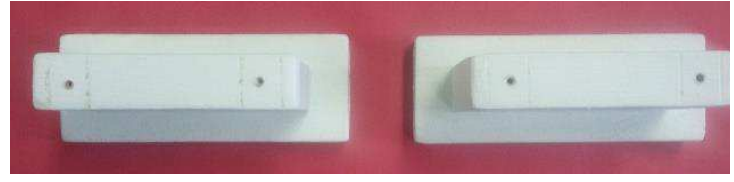

Fig. 2b-Vista superior base de madeira.

1 (um) pedaço de trilho de cortina $(100 \times 1,5) \mathrm{cm}$

1 (um) pedaço de trilho de cortina $(97,5 \times 1,5) \mathrm{cm}$

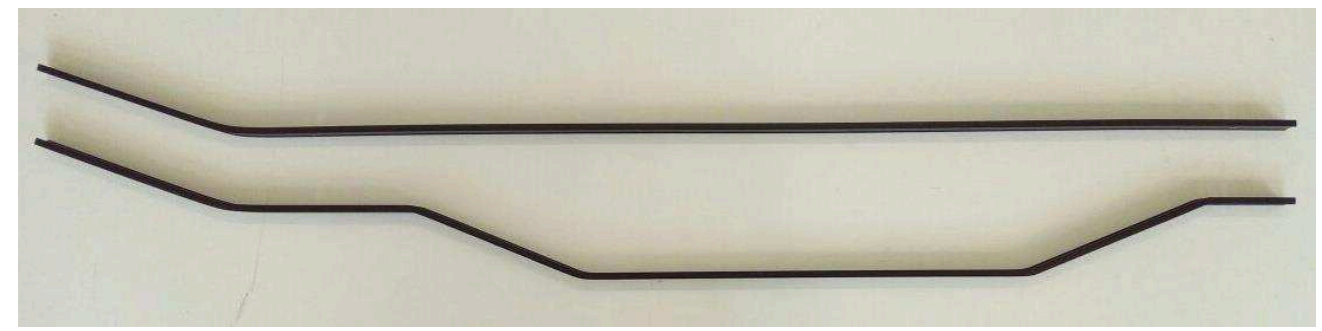

Fig. 3 - Imagem dos trilhos de cortina.

2 (duas) bolinhas de gude de mesma massa (5 g) e diâmetro 1,6 cm

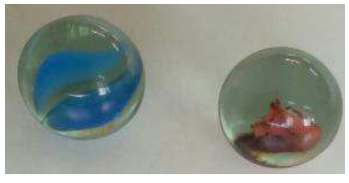

Fig. 4 - Imagem das bolinhas de gude.

1 (um) suporte de madeira para largada das bolinhas

1 (um) pedaço de papelão $(18 \times 8) \mathrm{cm}$

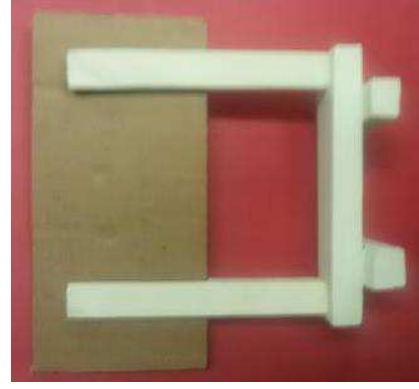

Fig. 5a - Vista lateral da base de madeira e da bandeirola de papelão.

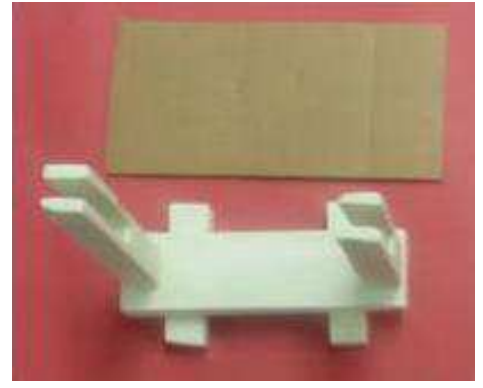

Fig. $5 b$ - Vista superior da base de madeira e da bandeirola de papelão.

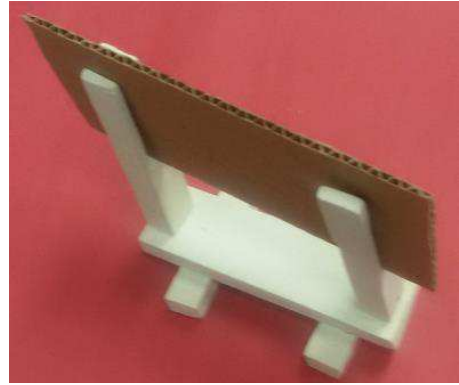

Fig. $5 c-$ Vista superior do conjunto base de madeira e da bandeirola de papelão. 
4 (quatro) parafusos para fixação dos trilhos sobre a madeira

Furadeira e brocas para metal e madeira

Fita métrica

Transferidor

Chave Philips

Alicate

\section{II.3 Montagem experimental}

A montagem do experimento é realizada de acordo com a Fig. 1. Após a seleção dos trilhos de cortina, são realizados nesses trilhos dobras com ângulos idênticos $\left(20^{\circ}\right)$, a uma distância de 15,5 cm da extremidade inicial, conforme Fig. 6.

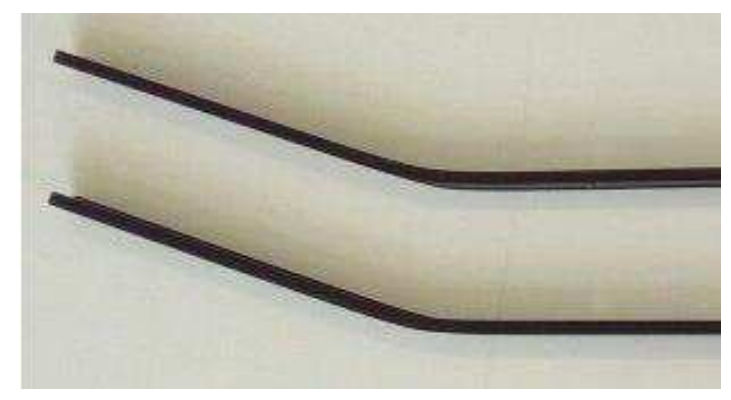

Fig. 6-Dobras realizadas nos trilhos com ângulos idênticos $\left(20^{\circ}\right)$.

Em seguida, nos dois trilhos, são mantidos deslocamentos retilíneos de $14 \mathrm{~cm}$ até atingirem os pontos $A_{1}$ e $A_{2}$, respectivos, conforme apresentados na Fig. 7.

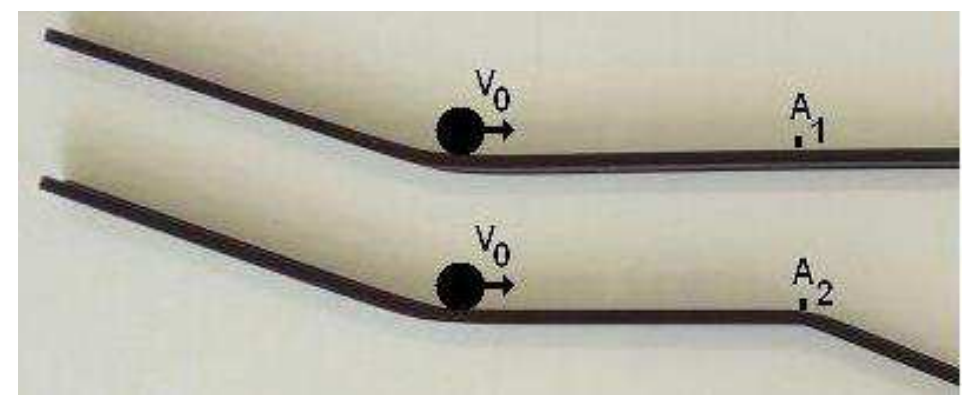

Fig. 7 - Após a dobra, deslocamentos retilíneos de $14 \mathrm{~cm}$ até atingir os pontos $A_{1}$ e $A_{2}$.

Os trilhos são montados em diferentes distâncias e devem representar diferentes trajetos, com declive e aclive ao longo da trajetória de apenas um dos trilhos. Vamos descrever o trajeto do trilho 2 (que representa um percurso com declive e aclive), quando comparado ao trajeto do trilho 1. Partindo dos pontos $A_{1}$ e $A_{2}$, são confeccionados diferentes percursos para os dois trilhos conforme Fig. 8. Enquanto no trilho 1, é mantida uma trajetória retilínea de 61 
$\mathrm{cm}$ até o ponto $C_{1}$, no trilho 2 são confeccionadas dobras com ângulos de $20^{0}$ nos pontos $A_{2} \mathrm{e}$ $\mathrm{B}_{2}$ (correspondentes aos pontos $\mathrm{A}_{1}$ e $\mathrm{B}_{1}$ respectivos do trilho 1 ), perfazendo assim uma distância $S$ de $14,5 \mathrm{~cm}$, que representa um declive entre os pontos $A_{2} B_{2}$.

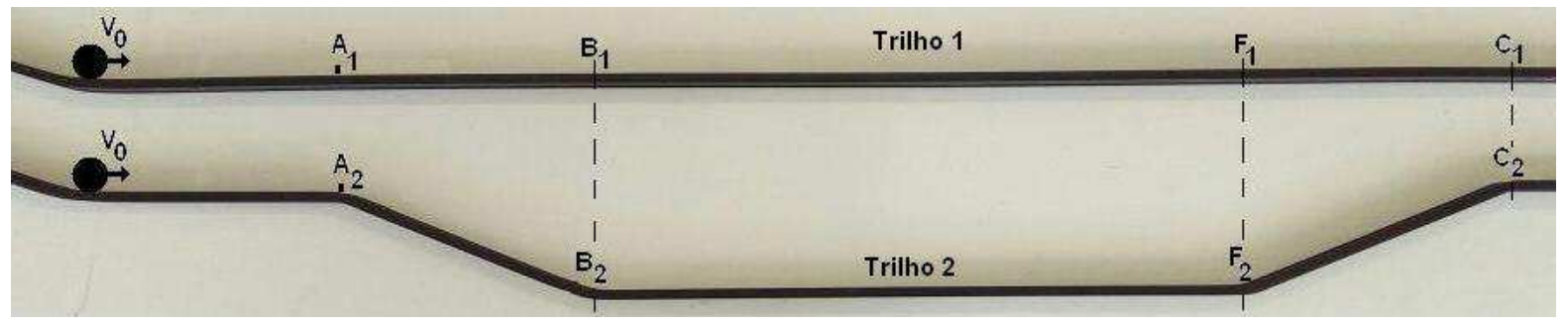

Fig. 8 - Imagem dos trilhos 1 e 2 com os diferentes percursos.

Em seguida, o trilho 2 mantém um comprimento retilíneo D igual a 34,5 cm entre os pontos $\mathrm{B}_{2} \mathrm{~F}_{2}$, conforme mostrado na Figura 8. E, finalmente, no trilho 2, são confeccionadas dobras com ângulos de $20^{0}$ nos pontos $\mathrm{F}_{2}$ e $\mathrm{C}_{2}$ (correspondentes aos pontos $\mathrm{F}_{1}$ e $\mathrm{C}_{1}$ respectivos do trilho 1), perfazendo assim novamente uma distância $S$ de $14,5 \mathrm{~cm}$, que representa um aclive entre os pontos $\mathrm{F}_{2} \mathrm{C}_{2}$. Em seguida, após a dobra com ângulo de $20^{0}$ no ponto $\mathrm{C}_{2}$ no trilho 2 , esse volta à mesma altura relativa ao trilho 1 , propiciando aos trilhos o equivalente à mesma altura. Após a equivalência das alturas nos dois trilhos, esses ainda apresentam uma reta de $7 \mathrm{~cm}$ até seu término.

Com o auxílio de uma furadeira, os trilhos foram furados e parafusados a uma mesma altura, na base de madeira (Fig. 9).

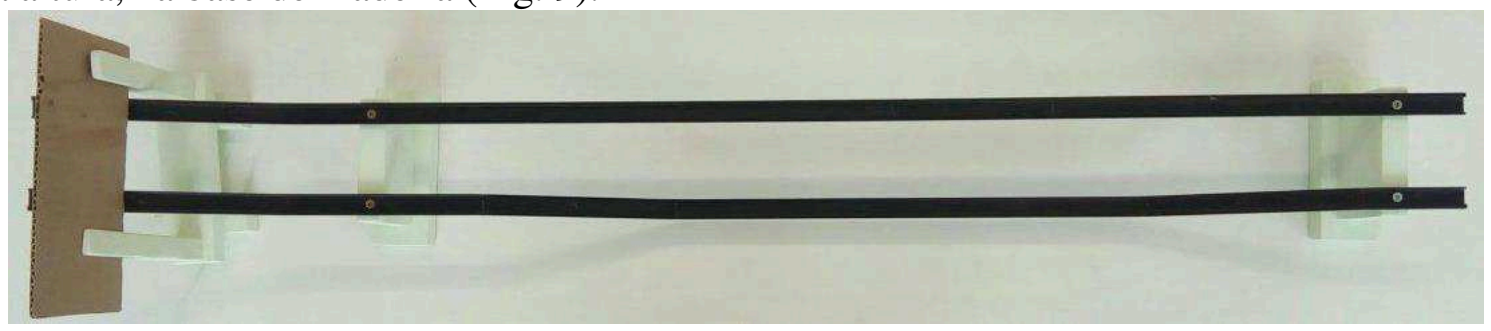

Fig. 9 - Vista superior dos trilhos 1 e 2 fixados com parafusos nas bases de madeira.

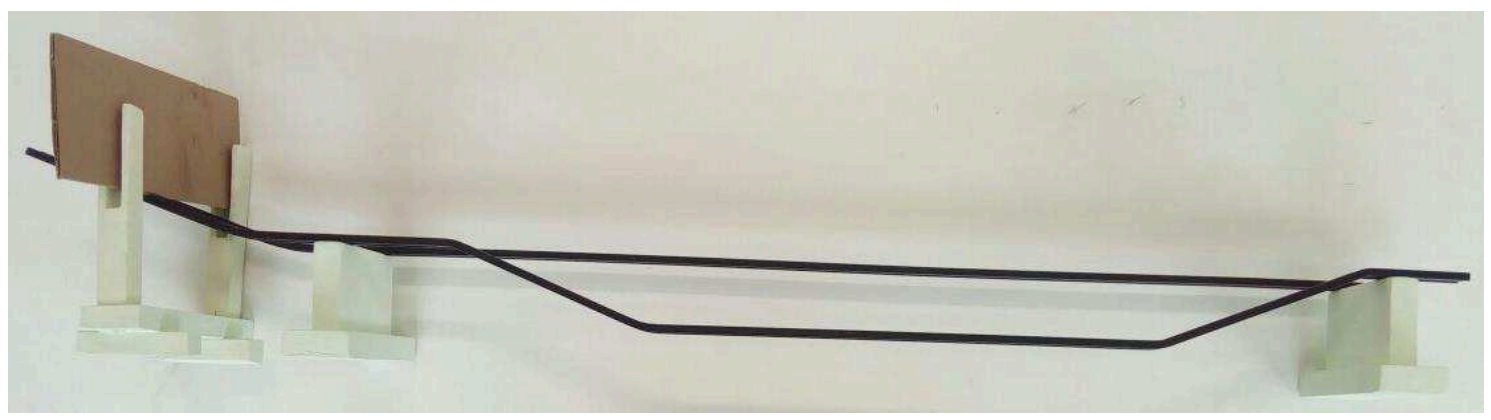

Fig. 10 - Vista lateral dos trilhos 1 e 2 fixados com parafusos nas bases de madeira. 
Após a fixação dos trilhos sobre as bases de madeira, para realizar o experimento, devem ser utilizadas duas bolinhas de gude colocadas em pontos de alturas iguais, nas partes iniciais inclinadas dos trilhos. Para que as bolinhas sejam abandonadas ao mesmo tempo da posição inicial (a mesma altura inicial nos dois trilhos), é utilizado um suporte de madeira com uma bandeirola de papelão móvel, que sustenta as bolinhas até o momento da largada. Nesse momento, essa bandeirola deve ser retirada subitamente mediante um movimento vertical e ascendente.

\section{Considerações finais}

A premissa de buscar respostas para qualquer problema que envolva o movimento de dinâmica de partículas, a partir do princípio da conservação da energia, induz a um mecanismo de interpretação rápida que muitas vezes pode estar influenciando os alunos a utilizarem recorrentemente esse princípio. Porém, na situação do presente experimento, a questão temporal que envolve o percurso das esferas não está relacionada à conservação de energia, mas ao menor tempo de deslocamento para atingir o ponto final. As esferas chegarem a esse ponto com a mesma velocidade não implica, necessariamente, atingirem o ponto final ao mesmo tempo.

Nessa perspectiva, é importante destacar que a conservação da energia mecânica permite vislumbrar que as esferas atingem o ponto final com a mesma velocidade. Porém, como o problema inicial colocado faz referência ao tempo de percurso, os alunos podem confundi-lo com a velocidade de chegada das esferas.

A utilização dessa atividade experimental de demonstração aberta pode propiciar o interesse do aluno em aprender e, com isso, viabilizar seu envolvimento cognitivo com os conceitos trabalhados. Esse envolvimento pode permitir que o aluno interprete os conceitos de movimento dos corpos e de conservação de energia mecânica, abordados, de forma significativa, superando, com isso, a prática da memorização e do uso automático de equações, sem compreensão do seu significado.

Nesse sentido, o uso dessa atividade (corrida de bolinhas) de forma aberta pode facilitar o desenvolvimento de habilidades que permitam aos alunos a elaboração de explicações coerentes para o fenômeno observado, fundamentadas nos conceitos envolvidos.

Pretendemos aplicar a presente proposta em sala de aula com o intuito de elaborarmos uma pesquisa contemplando discussões acerca das concepções dos alunos sobre o movimento das esferas e do desenvolvimento, por parte deles, dos conceitos envolvidos no experimento.

\section{Referências Bibliográficas}

ARAÚJO, M. S. T; ABIB, M. L. V. S. Atividades Experimentais no Ensino de Física: diferentes enfoques, diferentes finalidades. Revista Brasileira de Ensino de Física, São Paulo, v. 
25, n. 2, p. 176-194, June 2003. Disponível em: <http://www.scielo.br/scielo.php?script =sci_arttext\&pid=S1806-11172003000200007\&lng=en\&nrm=iso >. Acesso em: 25 out. 2017.

AZEVEDO, M. C. P. S. Ensino por investigação: problematizando as atividades em sala de aula. In: CARVALHO, A. M. P. (Org.). Ensino de Ciências: unindo a pesquisa a prática. São Paulo: Pioneira Thomson Learning, 2004. cap. 2, p. 19-33.

BAYERL. G. S. O ensino de ciências nos anos iniciais do ensino fundamental: uma reflexão histórica das políticas de educação no Brasil. In: IV SIMPÓSIO NACIONAL DE ENSINO DE CIÊNCIA E TECNOLOGIA, IV, 2014, Ponta Grossa. Atas...

BIASOTO, J. D.; CARVALHO, A. M. P. Análise de uma atividade experimental que desenvolva a argumentação dos alunos. In: ENCONTRO NACIONAL DE PESQUISA EM EDUCAÇÃO EM CIÊNCIAS, VI, 2007, Florianópolis. Atas...

BORGES, O. Formação inicial de professores de Física: formar mais! Formar melhor! Revista Brasileira de Ensino de Física, São Paulo, v. 28, n. 2, p. 135-142, 2006. Disponível em: $<$ http://www.scielo.br/scielo.php?script=sci_arttext\&pid=S1806-11172006000200003\&lng= en\&nrm=iso $>$. Accesso em: 24 Out. 2017.

DAHER, A. F. B.; MACHADO, V. M. Atividade Experimental Investigativa - uma possibilidade no ensino de Ciências nos anos iniciais. In: ENCONTRO NACIONAL DE PESQUISA EM EDUCAÇÃO EM CIÊNCIAS, XI, 2017, Florianópolis. Atas... Disponível em: $<$ http://www.abrapecnet.org.br/enpec/xi-enpec/anais/resumos/R1983-1.pdf> Acesso em: 20 fev. 2018.

FORÇA, A. C.; LABURÚ, C. E.; SILVA, O. H. M. da. Atividades Experimentais no Ensino de Física: Teoria e Práticas. In: ENCONTRO NACIONAL DE PESQUISA EM EDUCAÇÃO EM CIÊNCIAS, VIII e CONGRESSO IBEROAMERICANO DE INVESTIGACIÓN EM ENSEÑANZA DE LAS CIÊNCIAS, I, 2011, Campinas. Atas... Disponível em: $<$ http://www.nutes.ufrj.br/abrapec/viiienpec/resumos/R0035-1.pdf>. Acesso em: 16 nov. 2017.

MONTEIRO, P.C.; RODRIGUES, M.A.; SANTIN FILHO, O. Experimentos com abordagem investigativa propostos por licenciandos em Química. In: ENCONTRO NACIONAL DE PESQUISA EM EDUCAÇÃO EM CIÊNCIAS, XI, 2017, Florianópolis. Atas... Disponível em: <http://www.abrapecnet.org.br/enpec/xi-enpec/anais/resumos/R1530-1.pdf>. Acesso em: 20 fev. 2018.

OLIVEIRA, J. R. S. de. Contribuições e abordagens das atividades experimentais no ensino de ciências: reunindo elementos para a prática docente. Acta Scientiae, Canoas, v. 12, n. 1, p. 139-153, jan./jun. 2010. 
WARTHA, E. J.; LEMOS, M. M. Abordagens investigativas no ensino de Química: limites e possibilidades. Amazônia: Revista de Educação em Ciências e Matemática, Belém, v. 24, n. 12, p. 05-13, 2016.

ZÔMPERO, A. F.; LABURÚ, C. E. Atividades Investigativas no ensino de ciências: aspectos históricos e diferentes abordagens. Revista Ensaio, Belo Horizonte, v. 13, n. 3, p. 67-80, set./dez. 2011.

(c)) EY-NG-ND Direito autoral e licença de uso: Este artigo está licenciado sob uma Licença Creative Commons. 